\title{
Ppp2ca knockout in mice spermatogenesis
}

\author{
Xiaoyun Pan*, Xia Chen*, Xin Tong, Chao Tang and Jianmin Li \\ Key Laboratory of National Reproductive Medicine, Department of Cell Biology and Medical Genetics, \\ Nanjing Medical University, Nanjing, Jiangsu 210029, China
}

Correspondence should be addressed to J Li; Email: jianminlilab@163.com

${ }^{*}(\mathrm{X}$ Pan and X Chen are co-first authors and contributed equally to this work)

\begin{abstract}
Protein phosphatase 2A (PP2A) is a ubiquitous serine/threonine phosphatase involved in meiosis, mitosis, sperm capacitation, and apoptosis. Abberant activity of PP2A has been associated with a number of diseases. The homolog PPP2CA and PPP2CB can each function as the phosphatase catalytic subunit generally referred to as PP2AC. We generated a Ppp2ca conditional knockout (CKO) in C57BL/6) mice. Exon 2 of Ppp2ca was knocked out in a spatial or temporal-specific manner in primordial germ cells at E12.5. This Ppp2ca-null mutation caused infertility in male C57BL/6J mice. These CKO mice provide a powerful tool to study the mechanisms of Ppp2ca in development and disease.

Reproduction (2015) 149 385-391
\end{abstract}

\section{Introduction}

Protein phosphatase 2A (PP2A) is a ubiquitous serine/ threonine phosphatase involved in meiosis, mitosis, sperm capacitation, and apoptosis. Several studies have demonstrated a link between PP2A and a number of diseases (Janssens et al. 2005, Rivera \& Losada 2006, Krapf et al. 2010, Brestovitsky et al. 2011, Ruediger et al. 2011). Its catalytic subunit PP2AC plays a critical role in embryonic development and human diseases, such as Alzheimer's disease, cancer, and diabetes (Goedert et al. 1995, Zolnierowicz 2000, Kowluru 2005, Eichhorn et al. 2009, Liu \& Wang 2009). The homologues PPP2CA and PPP2CB can each function as the catalytic subunit of PP2A and are related to the male and female reproductive systems respectively. While the amino acid sequence of the two encoded proteins are very similar, PPP2CA is ten times more abundantly expressed than PPP2CB (Khew-Goodall et al. 1991). The PP2A phosphatase participates in the regulation of several cell-signaling pathways and cellular functions, including proliferation, cytoskeletal rearrangement, apoptosis, and cell migration (Janssens \& Goris 2001, Kong et al. 2004, 2007). It exists primarily as a heterotrimeric holoenzyme consisting of a structural A subunit, a regulatory $B$ subunit, and a catalytic $C$ subunit. Previous studies have specifically linked dysregulation of the catalytic subunit with several pathologies, including Alzheimer's disease, cancer, diabetes, and sperm capacitation. For example, SFK-mediated PP2AC phosphorylation inactivates PP2A and leads to mammalian sperm capacitation (Goto \& Harayama 2009, Krapf et al. 2010).

Interestingly, dysregulation of both PP2CA and PP2CB is associated with infertility. For example, Ppp2cb mRNA is upregulated in meiosis arrest female 1 (MARF1)-mutant mice, which results in meiotic arrest and female infertility (Su et al. 2012). Furthermore, mutant mice could undergo meiotic reversal if Ppp2cb was inhibited. Therefore, meiotic arrest in MARF1 mutant oocytes is dependent on upregulated $P p p 2 c b$ gene expression. The amino acid sequence of PPP2CA is $97 \%$ identical with PPP2CB and appears to play a role in embryonic development because null mutations lead to early embryonic lethality at E6.5 (Götz et al. 1998). It is possible that Ppp2ca is involved in WNT signaling, which controls epithelial-mesenchymal transition during vertebrate development (Peifer et al. 1994). As PP2A plays an important role in sperm capacitation, and Ppp2ca-null mutations are embryonic lethal, we bred a Ppp2ca conditional knockout (CKO) mouse with a loxP system to study the function of Ppp2ca in the male reproductive system.

Mvh, also known as DEAD (Asp-Glu-Ala-Asp) box polypeptide $4(D d x 4)$, is exclusively expressed in testicular germ cells. The MVH protein is localized in the cytoplasm of spermatocytes and round spermatids containing a perinuclear granule. The protein is also expressed in germ cells colonized in embryonic gonads, but is not detected in pluripotent embryonic cells, such as stem cells and germ cells (Fujiwara et al. 1994). A $D d x 4$-Cre mouse line displays active expression in 
primordial germ cells by E12.5 and maintains expression in germ cells for life (Tanaka et al. 2000). In this study, we employed Ddx4-Cre transgenic mice to specifically delete Ppp2ca in embryonic gonad tissues. These tissue-specific CKO mice were used to demonstrate that Ppp2ca is required for testicular development.

\section{Materials and methods}

\section{Construction of targeting plasmid}

Bacterial artificial chromosome (BAC) DNA extracted from DH10B cells was electroporated into SW106 cells, and then SW106 colonies containing the BAC were selected and confirmed with Ampicillin and BamHI digestion respectively. Two primer pairs (A/B; $Y / Z$ ) were used to amplify the homology arms from the BAC. These two homology arms were ligated into PL253, forming a target vector that was confirmed by PCR (primers $A / B ; Y / Z)$. The target vector was electroporated into the SW106 cells containing the BAC, and Ampicillin-resistant colonies were selected by PCR and BamHI and Sall digestion. The homology arms were amplified from the BAC by PCR (primers C/D; E/F), and then ligated into PL452 in a loxP-Neo/ kanamycin (Kan)-loxP cassette to produce the first loxP (1stloxP) plasmid. This plasmid was electroporated into $0.1 \%$ arabinose-treated SW106 cells, and kanamycin-resistant colonies were used for plasmid propagation following restriction enzyme mapping. The second LoxP site was inserted similarly into the gene-targeting vector (primers $\mathrm{G} / \mathrm{H} ; \mathrm{l} / \mathrm{J}$ ) and mapped by restriction enzyme digests (Fig. 1C). The completed targeting plasmid contained exon 2 between the two loxP sites and was verified by sequencing. The sequences of the primers used are listed below:

PPP2CA-A: AATAATGCGGCCGCAGCCATCCCTTTTACTCCTG; PPP2CA-B: AATAATAAGCTTTCTCTCTACTGTGTTCACCCTTC; PPP2CA-Y: AATAATAAGCTTGGTTGGTTAGTTATTTAGGTGGC; PPP2CA-Z: AATAATACTAGTTGATGGTTTGTGTATGCTTGG; PPP2CA-C: AATAATGCGGCCGCAACCCCAACAACAACCACA; PPP2CA-D: AATAATGAATTCCCTAGGCTCTCTCAAAAGAAACACCTGC; PPP2CA-E: AATAATGGATCCCAGCСТTTCTCТTСТССТTTG; PPP2CA-F: AATAATGTCGACCCTCGCCCCATTTCATCTAT; PPP2CA-G: AATAATGCGGCCGCAGGGCTTTTGTTCTCTTCTGT; PPP2CA-H: AATAATGAATTCGTTTAGGTATTTGCTCACTCTTGG; PPP2CA-I: AATAATGGATCCGGCATCGCACATCACCTA; PPP2CA-J: AATAATGTCGAC ACCATCTACTCTAAACTCTCCACTT.

\section{Generation of Ppp2ca ${ }^{\text {flox/+ }}$ mice and Ppp2ca ${ }^{\text {flox } /-}$ knockout mice}

The gene-targeting vector was linearized by restriction digest with Notl and then electroporated into C129 mouse embryonic stem (ES) cells. The electroporated ES cells were cultured with G418, and the resistant clones were screened for a successful recombination event by long-range PCR. The PCR primers used were specific for the neomycin cassette and upstream (Ppp2caFS5/ES-1R3) or downstream (Neo-F/pp2ca-RS2) of the respective $5^{\prime}$ or $3^{\prime}$ homology arms (Fig. 1D) resulting in PCR products $\sim 7 \mathrm{~kb}$ in length. The presence of the $3^{\prime}$ loxP site was also
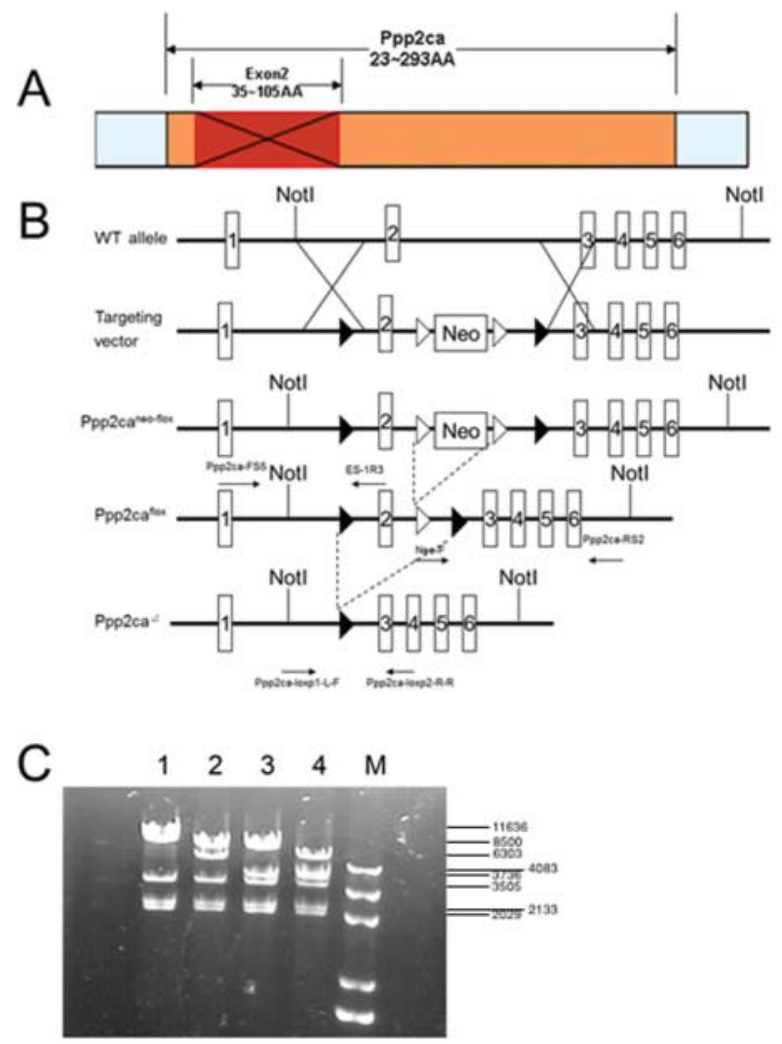

D

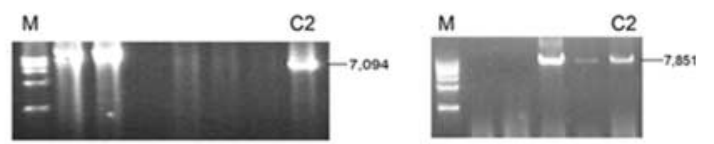

E

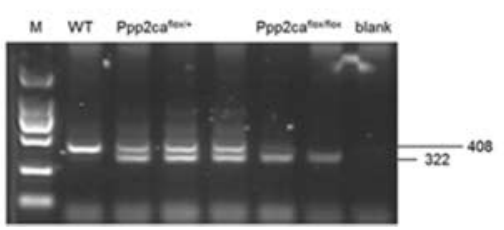

Figure 1 Generating a conditional null Ppp2ca allele. (A) The PPP2CA protein is made of 309 amino acids and the catalytic domain (light orange region) spans residues 23-293. The knockout region (dark orange region, crossed) spans amino acids 35-105. (B) Generation of Ppp2ca ${ }^{\text {flox }}$ mice. The Ppp2caallele spans nearly $30 \mathrm{~kb}$ from exon 1 to exon 7 (first row, scale). The targeted region spans exon 2 to exon 6 (second row). The targeting construct contains a silent mutation with a Notl site, and inserts a neo cassette flanked by frt sites (open triangles) into intron 2. This introduces a loxP site (black triangles) upstream of exon 2 but downstream of the neo cassette (third row). ES cells were screened for the Ppp2ca ${ }^{\text {flox }}$ allele using primers Ppp2caFS5/ES-1R3 and Neo-F/pp2ca-RS2 (fourth row). Ppp2ca ${ }^{\Delta}$ mice were identified with primers Ppp2ca-loxp1-L-F/Ppp2ca-loxp2-R-R (fifth row). (C) BamHI and Sall double digestion: M, marker; lane 1, PL253-Ppp2ca fragment; lane 2, PL253-Ppp2ca-1 stloxp fragment; lane 3, PL253-Ppp2ca1stloxp-popout fragment; lane 4, PL253-Ppp2ca-targeting vector fragment. (D) ES clones were screened for a successful recombination event by a longrange PCR. (left panel) PCR screening with primer pair Ppp2ca-FS5/ES-1R3 yields a 7094-bpproduct upstream of the $5^{\prime}$ homology arm. (right panel) PCR screening with primer pair Neo-F/pp2ca-RS2 yields a 7851 bp product downstream of the $3^{\prime}$ homology arm. M, marker. (E) Primer pair Ppp2ca-F/R distinguishes Ppp2ca floxflox mice (322 bp) from WT mice (408 bp). 


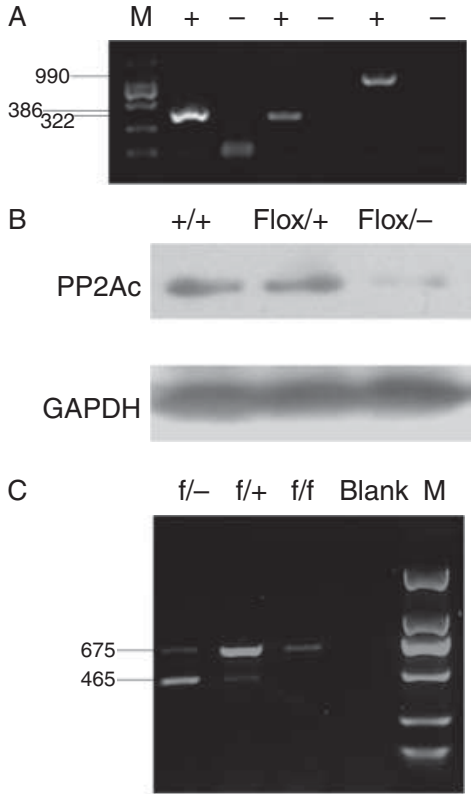

Figure 2 Decreased Ppp2ca expression in mutant mice. (A) Ppp2ca ${ }^{\text {flox/- }}$; $D d x 4-C r e$ is identified by PCR. Lanes 2 and 3: Ddx4-Cre is identified with primer CRE-F/R (364 bp). Lanes 4 and 5: flox is identified with primer Ppp2ca-F/R (322 bp). Lanes 6 and 7: knockout fragment between the two loxP sites is identified with primer Ppp2ca-loxp1-L-F/Ppp2ca-loxp2-R-R (1024 bp). M, marker. (B) Testes of WT mice, Ppp2ca ${ }^{\text {flox/t+ }}$ mice, and Ppp2 $\mathrm{ca}^{\text {flox/ }}$ - littermates were tested for PPP2CA protein expression by western blotting analysis using PP2Ac antibody. There was a dramatic reduction in the expression of $\mathrm{PP} 2 \mathrm{AC}$ in mutant mice, and any protein detected may have been the product of the homolog Ppp2cb. GAPDH was used as the loading control. (C) Gene expression in the testes of Ppp2 $\mathrm{Ca}^{\text {flox } /-}, \mathrm{Ppp} 2 \mathrm{Ca}^{\text {flox } /+}$, and WT mice was determined by reverse transcription PCR. The mutant mice had shorter transcripts than control mice, indicating successful knockout. Background Ppp2ca expression in the mutant samples could be from nontesticular cells present in our samples.

validated using PCR primers that flanked the loxP site. Of the 20 G418-resistant clones, one had a homologous recombination event. ES cells from this clone $(\mathrm{C} 2)$ were microinjected into $\mathrm{C} 57 \mathrm{BL} / 6 \mathrm{~J}$ blastocysts to generate chimeric mice. The chimeric mice (Ppp2ca-loxp1-L-F/ES-1R3; Neo-F/Ppp2ca-loxp2-R-R) were then bred with $\mathrm{C} 57 \mathrm{BL} / 6 \mathrm{~J}$ mice to verify germline transmission of the targeted allele. The Ppp2ca flox/+ mice were genotyped by PCR (Ppp2ca-F/R). Subsequently, we bred the Ppp2ca flox/+ mice to obtain homozygous Ppp2ca flox/flox mice. To achieve germ cell-specific deletion of Ppp2ca, female homozygous flox mice were crossed with male $D d x 4$-Cre transgenic mice (germ cell-specific Cre line, \#006954, Jackson Laboratory, Bar Harbor, ME, USA). The male heterozygous progeny that bears the genotype Ppp2 $\mathrm{Ca}^{\text {flox } /+} ; \mathrm{Dd} \times 4$-Cre (Cre-F/R; Ppp2ca-F/R) was mated with the female Ppp2ca $a^{\text {flox/flox }}$ mice to obtain Ppp2ca ${ }^{\text {flox/-}}$; Ddx4-Cremice (Cre-F/R; Ppp2ca-F/R; Ppp2ca-loxp1-L-F/Ppp2ca-loxp2-R-R). This study was approved by the Institutional Animal Care and Use Committee of Nanjing Medical University (Number: NJMU-IACUC-20100601001). The sequences of the primers used are listed below:

Ppp2ca-FS5: CCCCCCCTCTTCTTCCTCCT; ES-1R3: AAGGGTTATTGAATATGATCGGA; Neo-F: CGTTGGCTACCCGTGATATTTAGAGCTTGCGGAACCCTTCG; Ppp2ca-RS2:
GGTTGAaGACCTAGTAACTCATACAAG; Ppp2ca-loxp1-L-F: AATAATGCGGCCGCAACCCCAACAACAACCACA; Ppp2caloxp2-R-R: AATAATGTCGACACCATCTACTCTAAACTCTCCACTT Cre-F: TTGCCTGCATTACCGGTCGATGC; Cre-R: TTGCACGTTCACCGGCATCAACG.

\section{Western blotting analysis}

Western blot analysis of endogenous proteins from organ tissues was performed as described previously (Brestovitsky et al. 2011). The following antibodies were used: rabbit monoclonal PP2AC antibody (Cell Signaling Technology, Inc., Beverly, MA, USA), rabbit monoclonal glyceraldehyde-3phosphate dehydrogenase (GAPDH) antibody (Sigma-Aldrich), and goat anti-rabbit IgG-HRP antibody (Sigma-Aldrich). Visualization was acheived with the SuperSignal West Pico Chemiluminescent Substrate (Thermo Fisher Scientific, Inc., Waltham, MA, USA).

\section{RNA preparation and RT-PCR}

RNA was extracted from testicular cells using RNAiso Plus following the manufacturer's protocol (TaKaRa, Dalian, China). To obtain cDNA, the PrimeScriptTM Reverse Transcription Reagent Kit with gDNA Eraser (TaKaRa) was used with random primers (Invitrogen). The sequences of the specific primers used for PCR are listed below:

Mpp2ca-P5F: GGTCAAGAGCCTCTGCGAGAA; Mpp2caP5R1: CCGGTCATGGCACCAGTTAT.

\section{DNA content assay}

The testicular cells of mice at P38 and P56 were analyzed by flow cytometric analysis to quantify the number of haploid, diploid, and tetraploid cells.
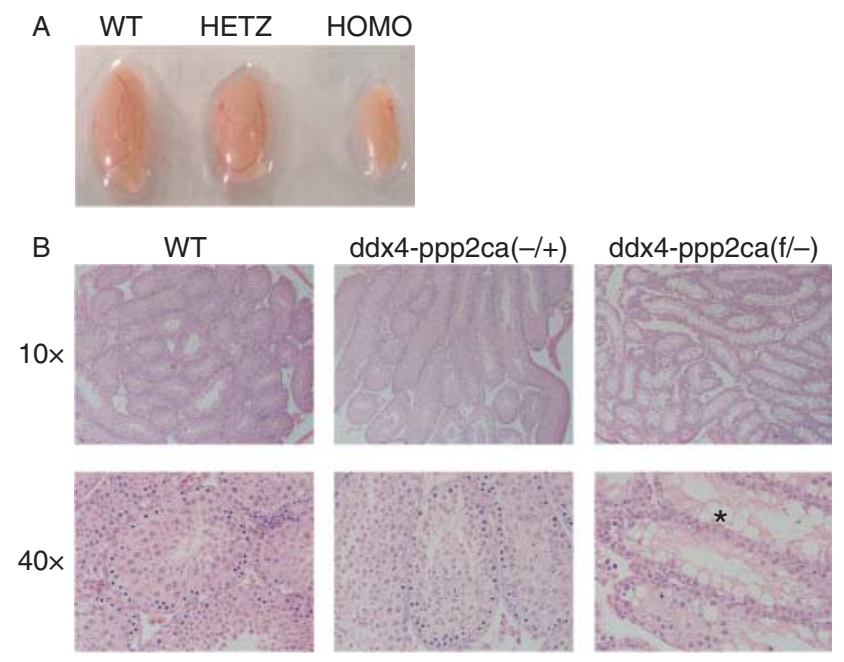

Figure 3 Phosphatase function is required for normal spermatogenesis. (A) Mice testes at 4 weeks. Left to right: WT, heterozygous, and mutant. The mutant testes were significantly reduced in size compared with the WT. (B) Mutant tubules with vacuolation $\left({ }^{*}\right)$ and disrupted morphology as observed by $\mathrm{H} \& \mathrm{E}$ staining of the seminiferous tubules. 
A

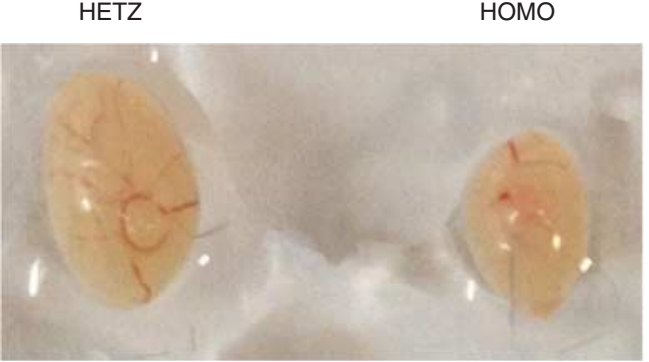

B

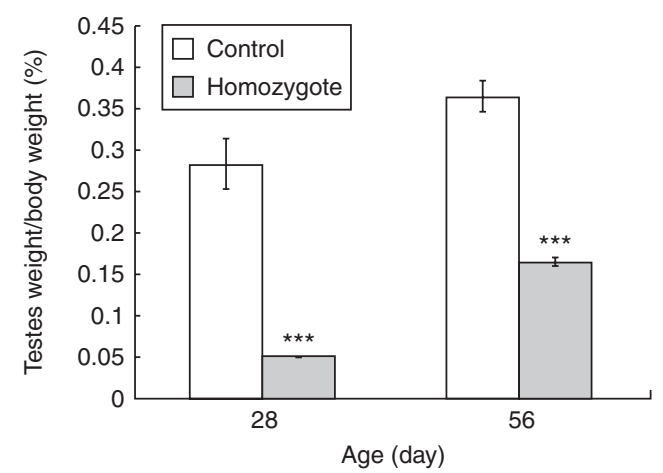

C
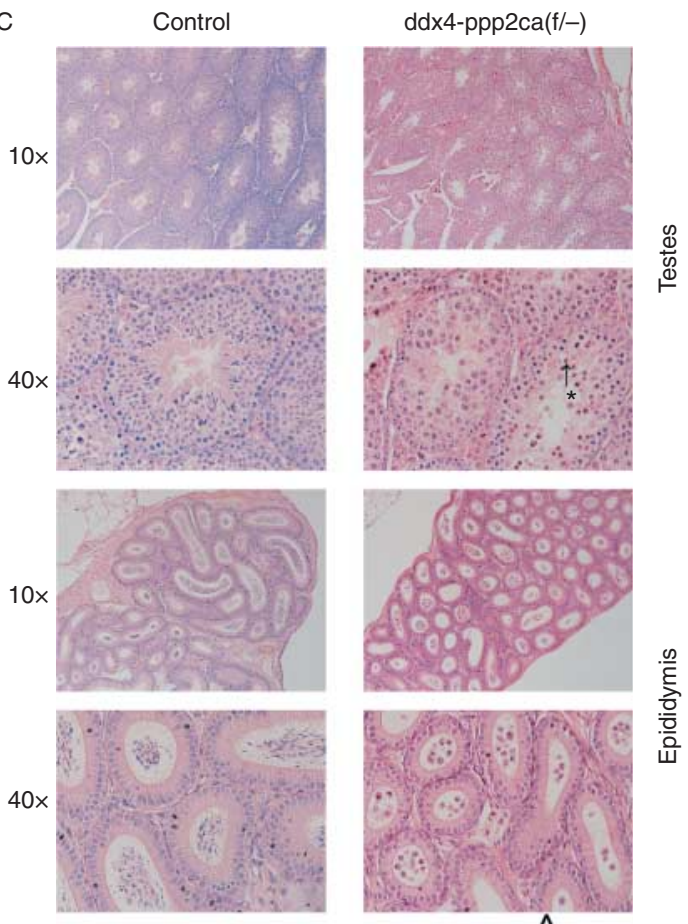

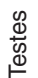
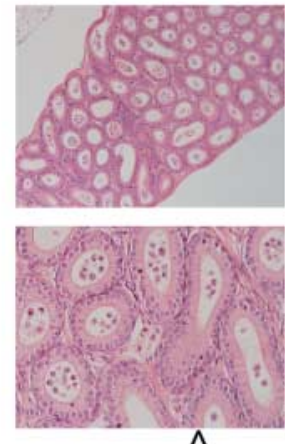

$\frac{\text { 을 }}{\text { 음 }}$

Figure 4 Decreased Ppp2ca expression at 8 weeks. (A) The testes on the left is from an 8-week-old control mouse, and the one on the right is from an 8-week-old mutant mouse. (B) The weight of testes from mutant mice (Homoz) and normal mice at 4 and 8 weeks. (C) Mutant testes were almost completely lacking in mature spermatozoa, as observed by $\mathrm{H} \& \mathrm{E}$ staining of the seminiferous tubules and epididymides. The mutant tubules exhibited vacuolation $(*)$, incorrect placement of cell types (arrow), and lacked elongated spermatozoa. The mutant epididymides contained some round cells $(\wedge)$ of different sizes and shapes, and no normal sperm. Results are mean \pm S.E.M. ( $n=3$ animals/genotype), $* * * P<0.001$ vs controls.

\section{Sperm smear}

The epididymides of killed mice were minced and then placed in tubes with $200 \mu \mathrm{l}$ of PBS for a 5 min incubation in a $37^{\circ} \mathrm{C}$ water bath. A sample of the supernatant $(10 \mu \mathrm{l})$ was pipetted dropwise on to a glass slide, covered with a coverslip, and allowed to dry at room temperature. The slides were then fixed in $4 \%$ paraformaldehyde for $40-60 \mathrm{~min}$ and rinsed in PBS for $5 \mathrm{~min}$, followed by staining with hematoxylin and eosin (H\&E).

\section{Fertility testing}

To test for fertility, 8-week-old male mice were randomly divided into control and experimental groups according to genotype. Each male mouse was housed with two 8-week-old C57/B6 female mice for 1 week. Following co-housing, the female mice were killed, and the number of embryos within the uterine horns was determined. Live embryos were taken as an indication of male fertility.

\section{Results}

\section{Generating a conditional null Ppp2ca allele}

There are seven exons in the mouse Ppp2ca gene, spanning $\sim 30 \mathrm{~kb}$ (Khew-Goodall et al. 1991). In one reported Ppp2ca knockout more than $0.5 \mathrm{~kb}$ of the promoter, exon 1 , and $0.3 \mathrm{~kb}$ of intron 1 are replaced by a neomycin (neo) resistance cassette, which leads to early-embryonic lethality at E6.5 (18). The catalytic domain of PPP2CA spans amino acid 23-293. We designed a conditional targeting vector spanning $\sim 2.2 \mathrm{~kb}$ to disrupt exon 2, which encodes amino acids 35-105 (Fig. 1A). To construct the conditional genetargeting vector, we used recombination to introduce loxp sites at each end of exon 2 in a vector containing positive and negative markers for selection (Fig. 1B). Positive clones were identified by PCR and enzyme digestion (Fig. 1C). The plasmid containing the loxP sites and positive and negative selection markers was then electroporated into ES cells. Long-range PCR was then used to verify the 24 selected colonies and colony $\mathrm{C} 2$ that carried the Ppp2ca CKO allele (Fig. 1D). C2 clones were microinjected into $\mathrm{C} 57 \mathrm{BL} / 6 \mathrm{~J}$ blastocysts to generate chimeric animals. The heterozygous Ppp2ca flox $/+$ offspring were viable, fertile, and did not display any obvious abnormalities. Next, we bred Ppp2 $\mathrm{ca}^{\text {flox } /+}$ mice together to obtain Ppp2ca ${ }^{\text {flox/flox }}$ mice (Fig. 1E), which were also fertile and did not exhibit any obvious abnormalities.

\section{Decreased Ppp2ca expression in mutant mice}

To examine whether Ppp2ca plays a role in the male reproductive system, we applied a Cre-loxP system to ablate Ppp2ca expression in developing testes. Floxed Ppp2ca mice were bred with the Ddx4-Cre line. By utilizing this Cre line, we were able to examine 
Table 1 Decreased levels of Ppp2ca expression caused male infertility.

\begin{tabular}{|c|c|c|c|c|}
\hline \multicolumn{2}{|c|}{ Male } & \multicolumn{2}{|c|}{ Female } & \multirow{2}{*}{$\begin{array}{c}\text { Average } \\
\text { number of } \\
\text { pups }\end{array}$} \\
\hline Genotype & Number & Genotype & Number & \\
\hline Control & 7 & WT & 14 & $7.93 \pm 2.08$ \\
\hline Mutant & 7 & WT & 14 & 0 \\
\hline
\end{tabular}

Seven control mice and seven mutant mice were used for comparison; the seven mutant males produced no pups.

the functions of Ppp2ca in the male reproductive system. From this, we obtained the Ppp2 $\mathrm{Ca}^{-1+} ; \mathrm{Dd} \times 4$-Cre (heterozygous) lines and the Ppp2ca $\mathrm{flox}^{-}$; Ddx4-Cre (mutant) lines (Fig. 2A). The mutant mice were infertile; therefore, Ppp2ca was not expressed in testes. Next, we examined the protein expression of PPP2CA in the testes of the different mouse strains. Compared with control testes, there were low levels of expression in the testes of mutant mice (Fig. 2B) using a PP2Ac antibody. As mutational protein expression was not observed, expression at the RNA level was determined. Due to the Cre-lox recombination, Ppp2ca transcripts were shorter in mutant mice than in control mice (Fig. 2C).

\section{Phosphatase function is essential for normal spermatogenesis}

The testicular morphology of mutant mice and WT mice were completely different at 4 weeks. For example, there was a significant reduction in the size and weight of the testes (Fig. 3A and B). The mutant testes were $\sim 20 \%$ the weight of the control testes, but there was no significant reduction in the overall weight of the mutant mice (Fig. 4B). Normal tubules containing spermatogonia, primary spermatocytes, and secondary spermatocytes were not observed in the mutant testes. Instead, the mutant tubules contained a large number of vacuolation structures, and any spermatogonia or primary spermatocytes were arranged in a disorderly manner. However, there was no difference in the testicular morphology and size between the heterozygous and WT mice at 4 weeks (Fig. 3B).

By 8 weeks, the mutant testes were approximately half the weight of the control testes (Fig. 4A and B), and there were fewer vacuole-like structures in the tubules. Compared with the control, the germ cells in the mutant tubules were disorganized and lacked elongated spermatozoa (Fig. 4C). Based on these results, the function of Ppp2ca is essential for normal spermatogenesis.

\section{Decreased expression of Ppp2ca caused male infertility}

At 8 weeks, the seminiferous tubules of normal mice contain spermatogonia, primary and secondary spermatocytes, spermatids, and sperm. In the mutant mice, however, the cells were similar to primary spermatocytestage cells, chromatin agglutination was abnormal and scattered, and there was a lack of normal spermatozoa in the testes (Fig. 4B). Overall, the process of spermatogenesis was disordered in the mutant testes; at all levels, reproductive cells were arranged in a disorderly manner or were completely absent. In normal mice, the epididymis tubules at the tail of the epididymis contained many sperm. The mutant epididymides contained some round cells of different sizes and shapes, but nothing resembling normal sperm (Fig. 4B). The male mutant mice infertility was determined by fertility testing (Table 1 ). Therefore, Ppp2ca deficiency can cause male infertility.

\section{Ppp2ca-deficient mice were incapable of generating normal sperm}

It remained uncertain at which stage Ppp2ca influenced sperm production. First, the haploid, diploid, and tetraploid cells in the testes of mice at P38 were investigated by flow cytometric analysis. Compared with the control group, meiosis was blocked at the diploid stage in cells from mutant mice (Fig. 5A1). This result indicated that the gene influences meiosis at younger ages. We also examined the haploid, diploid, and tetraploid cells in testes of adult mice at P56. Surprisingly, the number of haploid and diploid cells in testes were almost the same (Fig. 5A2). This

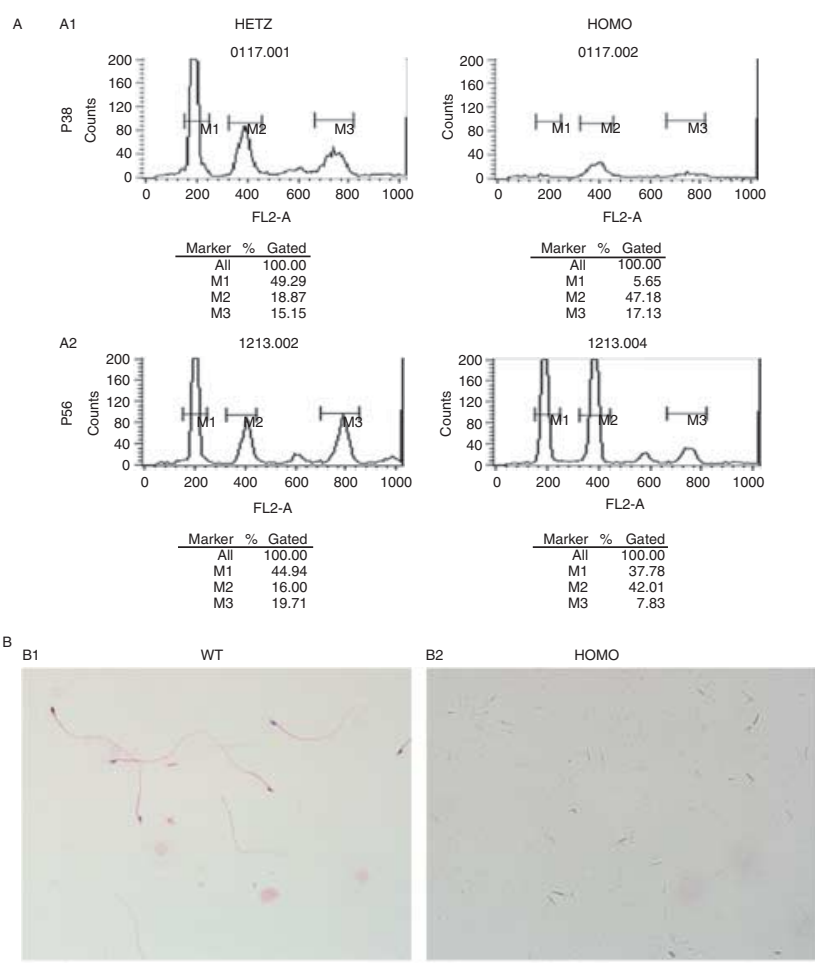

Figure 5 Decreased Ppp2ca expression reduced normal sperm count in the epididymides. (A) Flow cytometric analysis of haploid, diploid, and tetraploid cells in P38 and P56 testes. M1, M2, and M3 populations correspond to $1 \mathrm{C}, 2 \mathrm{C}$, and $4 \mathrm{C}$ cells respectively. (B left panel) Sperm from control (WT) epididymides. (B right panel) Normal sperm were not observed in the mutant sperm smear.Experiments had been repeated. 
demonstrated that meiosis was still blocked in the diploid stage, but some cells could proceed to the next stage as the mouse aged. However, normal sperm were not observed in a sperm smear collected from the mutant epididymides at P56 (Fig. 5B1 and B2). Although there were still haploid cells in testes of mice at P56, these sperm were not normal.

\section{Discussion}

It is well known that PP2Ac is expressed abundantly in testis (Hatano et al. 1993) and plays an important role in embryonic development and sperm capacitation. Based on these facts, we set out to determine the homologue responsible in these mechanisms. Therefore, we generated conditional Ppp2ca knockouts to deteremine whether the loss of expression in mouse testes caused testicular morphological changes or infertility.

Previously, our laboratory demonstrated that knockout of exons 3-5 of Ppp2ca resulted in testicular morphological changes and infertility. In comparison, the knockout of exon 2 delayed morphological changes, and the vacuole-like structures increased significantly. We have yet to determine whether these delayed changes are the result of exon 2 deletion or whether the rest of PP2Ac delays the changes.

Disruption of PP2A activity will lead to meiotic arrest. Specifically, PP2A prevents the cleavage of centromeric cohesin during meiosis I by counteracting CK1-mediated phosphorylation of REC8, which activates separase (Ishiguro et al. 2010). Our results suggest that deletion of Ppp2ca causes male infertility. Therefore, we surmise that an arrest in meiosis leads to infertility. We plan to investigate whether meiosis is blocked in Ppp2caknockout cells, and which stage of meiosis is blocked.

PP2AC is the catalytic subunit critical for the function of PP2A. Ppp2ca is an important homolog that can function as the PP2AC subunit. We hypothesized that the loss of Ppp2ca would affect testicular morphology. However, Ppp2ca is also known to perform other critical functions as well. For instance, decreased Ppp2ca expression has been associated with Alzheimer's disease and other tauopathies (Planel et al. 2007, Whittington et al. 2011), which indicates that it plays a role in regulating phosphorylation in the brain. In addition, PP2A was shown to play a role in cardiomyocyte cell death by regulating calcium ion $\left(\mathrm{Ca}^{2+}\right)$ signaling (Ferron et al. 2011). Further investigations are necessary to determine the importance of Ppp2ca gene function in other organs.

\section{Declaration of interest}

The authors declare that there is no conflict of interest that could be perceived as prejudicing the impartiality of the research reported.

\section{Funding}

This work was supported by grants from the National Natural Science Foundation of China (NFSC, nos 81100413, 31171443, and 30971092), and the National Basic Research Program of China (973 Program, no. 2009CB941700).

\section{References}

Brestovitsky A, Sharf R, Mittelman K \& Kleinberger T 2011 The adenovirus E4orf4 protein targets PP2A to the ACF chromatin-remodeling factor and induces cell death through regulation of SNF2h-containing complexes. Nucleic Acids Research 39 6414-6427. (doi:10.1093/nar/gkr231)

Eichhorn P, Creyghton MP \& Bernards R 2009 Protein phosphatase 2A regulatory subunits and cancer. Biochimica et Biophysica Acta 1795 $1-15$.

Ferron L, Ruchon Y, Renaud J-F \& Capuano V 2011 T-type $\mathrm{Ca}^{2+}$ signalling regulates aldosterone-induced CREB activation and cell death through PP2A activation in neonatal cardiomyocytes. Cardiovascular Research 90 105-112. (doi:10.1093/cvr/cvq379)

Fujiwara Y, Komiya T, Kawabata H, Sato M, Fujimoto H, Furusawa M \& Noce T 1994 Isolation of a DEAD-family protein gene that encodes a murine homolog of Drosophila vasa and its specific expression in germ cell lineage. PNAS 91 12258-12262. (doi:10.1073/pnas.91.25.12258)

Goedert M, Jakes R, Qi Z, Wang J \& Cohen P 1995 Protein phosphatase 2A is the major enzyme in brain that dephosphorylates tau protein phosphorylated by proline-directed protein kinases or cyclic AMPdependent protein kinase. Journal of Neurochemistry 65 2804-2807. (doi:10.1046/j.1471-4159.1995.65062804.x)

Goto N \& Harayama H 2009 Calyculin A-sensitive protein phosphatases are involved in maintenance of progressive movement in mouse spermatozoa in vitro by suppression of autophosphorylation of protein kinase A. Journal of Reproduction and Development 55 327-334. (doi:10.1262/jrd.20170)

Götz J, Probst A, Ehler E, Hemmings B \& Kues W 1998 Delayed embryonic lethality in mice lacking protein phosphatase 2A catalytic subunit $\mathrm{C} \alpha$. PNAS 95 12370-12375.

Hatano Y, Shima H, Haneji T, Miura AB, Sugimura T \& Nagao M 1993 Expression of PP2A B regulatory subunit $\beta$ isotype in rat testis. FEBS Letters 324 71-75. (doi:10.1016/0014-5793(93)81535-8)

Ishiguro T, Tanaka K, Sakuno T \& Watanabe Y 2010 Shugoshin-PP2A counteracts casein-kinase-1-dependent cleavage of Rec8 by separase. Nature Cell Biology 12 500-506. (doi:10.1038/ncb2052)

Janssens V \& Goris J 2001 Protein phosphatase 2A: a highly regulated family of serine/threonine phosphatases implicated in cell growth and signalling. Biochemical Journal 353 417-439. (doi:10.1042/0264-6021: 3530417)

Janssens V, Goris J \& Van Hoof C 2005 PP2A: the expected tumor suppressor. Current Opinion in Genetics \& Development 15 34-41. (doi:10.1016/j.gde.2004.12.004)

Khew-Goodall Y, Mayer RE, Maurer F, Stone SR \& Hemmings BA 1991 Structure and transcriptional regulation of protein phosphatase $2 \mathrm{~A}$ catalytic subunit genes. Biochemistry 30 89-97. (doi:10.1021/ bi00215a014)

Kong M, Fox CJ, Mu J, Solt L, Xu A, Cinalli RM, Birnbaum MJ, Lindsten T \& Thompson CB 2004 The PP2A-associated protein $\alpha 4$ is an essential inhibitor of apoptosis. Science 306 695-698. (doi:10.1126/science. 1100537)

Kong M, Bui TV, Ditsworth D, Gruber J, Goncharov D, Krymskaya VP, Lindsten T \& Thompson CB 2007 The PP2A-associated protein $\alpha 4$ plays a critical role in the regulation of cell spreading and migration. Journal of Biological Chemistry 282 29712-29720. (doi:10.1074/jbc. M703159200)

Kowluru A 2005 Novel regulatory roles for protein phosphatase-2A in the islet $\beta$ cell. Biochemical Pharmacology 69 1681-1691. (doi:10.1016/ j.bcp.2005.03.018)

Krapf D, Arcelay E, Wertheimer EV, Sanjay A, Pilder SH, Salicioni AM \& Visconti PE 2010 Inhibition of Ser/Thr phosphatases induces 
capacitation-associated signaling in the presence of Src kinase inhibitors. Journal of Biological Chemistry 285 7977-7985. (doi:10.1074/jbc. M109.085845)

Liu R \& Wang J-Z 2009 Protein phosphatase 2A in Alzheimer's disease. Pathophysiology 16 273-277. (doi:10.1016/j.pathophys.2009.02.008)

Peifer M, Pai L-M \& Casey M 1994 Phosphorylation of the Drosophila adherens junction protein armadillo: roles for wingless signal and zestewhite 3 kinase. Developmental Biology 166 543-556. (doi:10.1006/ dbio.1994.1336)

Planel E, Richter KE, Nolan CE, Finley JE, Liu L, Wen Y, Krishnamurthy P, Herman M, Wang L \& Schachter JB 2007 Anesthesia leads to tau hyperphosphorylation through inhibition of phosphatase activity by hypothermia. Journal of Neuroscience 27 3090-3097. (doi:10.1523/ JNEUROSCI.4854-06.2007)

Rivera T \& Losada A 2006 Shugoshin and PP2A, shared duties at the centromere. BioEssays 28 775-779. (doi:10.1002/bies.20448)

Ruediger R, Ruiz J \& Walter G 2011 Human cancer-associated mutations in the $\mathrm{A} \alpha$ subunit of protein phosphatase $2 \mathrm{~A}$ increase lung cancer incidence in A $\alpha$ knock-in and knockout mice. Molecular and Cellular Biology 31 3832-3844. (doi:10.1128/MCB.05744-11)
Su Y-Q, Sugiura K, Sun F, Pendola JK, Cox GA, Handel MA, Schimenti JC \& Eppig JJ 2012 MARF1 regulates essential oogenic processes in mice. Science 335 1496-1499. (doi:10.1126/science.1214680)

Tanaka SS, Toyooka Y, Akasu R, Katoh-Fukui Y, Nakahara Y, Suzuki R, Yokoyama M \& Noce T 2000 The mouse homolog of Drosophila vasa is required for the development of male germ cells. Genes and Development 14 841-853.

Whittington RA, Virág L, Marcouiller F, Papon M-A, Khoury NBE, Julien C, Morin F, Emala CW \& Planel E 2011 Propofol directly increases tau phosphorylation. PLoS ONE 6 e16648. (doi:10.1371/journal.pone.0016648) Zolnierowicz S 2000 Type 2A protein phosphatase, the complex regulator of numerous signaling pathways. Biochemical Pharmacology 60 1225-1235. (doi:10.1016/S0006-2952(00)00424-X)

Received 14 May 2014

First decision 11 June 2014

Revised manuscript received 9 December 2014

Accepted 26 January 2015 